\title{
Total earlobe reconstruction with a superiorly based preauricular flap*
}

João Goulão ${ }^{1}$
João Alves ${ }^{1}$

DOI: http:/ / dx.doi.org/10.1590/abd1806-4841.20163897

\begin{abstract}
An 86-year-old woman was referred for treatment of a lentigo maligna melanoma on the left earlobe, confirmed by cutaneous biopsy. The resulting surgical defect involved the earlobe's full thickness. The authors outline a simple method for reconstructing the entire lobe in one stage, without grafts, whilst offering a pleasant appearance. Earlobe deformity may be congenital or, more often, acquired due to trauma, burns or surgery. Ear lobules are an important reference point for facial symmetry and they serve decorative purposes like wearing earrings. Losing them represents an obvious aesthetic abnormality. Several methods developed to reconstruct this deformity have presented various advantages and disadvantages.
\end{abstract}

Keywords: Ear neoplasms; Melanoma; Reconstruction.

\section{INTRODUCTION}

An 86-year-old woman was referred for treatment of a lentigo maligna melanoma on the left earlobe, confirmed by cutaneous biopsy (Figure 1). There were no enlarged lymph nodes. The lesion was removed with $5 \mathrm{~mm}$ surgical margins. The resulting surgical defect involved the earlobe's full thickness (Figure 2).

The authors outline a simple method for reconstructing the entire lobe in one stage, without grafts, whilst offering a pleasant appearance.

\section{CASE REPORT}

Surgery was performed under local anaesthesia (1\% lidocaine without adrenaline). The tumor and a $5 \mathrm{~mm}$ margin were excised, leaving a surgical defect affecting the whole lobule (Figure 2). Since the patient had redundant skin in the preauricular area, the authors decided to use that region for earlobe reconstruction. A superiorly based transposition flap, with the required dimensions to reach and cover the defect, was marked in the preauricular area. 
To preserve the anatomy and symmetry, the amputated earlobe was used as a model to reconstruct the new earlobe, providing the appropriate flap measurements. Its length corresponds to twice the width of the anterior surface of the lobule, plus $3-4 \mathrm{~mm}$ to enable the flap to fold upon itself. Furthermore, its width is equal to $1-2 \mathrm{~mm}$, plus the height of the lobule, to compensate for expected flap contraction.



Figure 1 :

Earlobe lentigo maligno melanoma

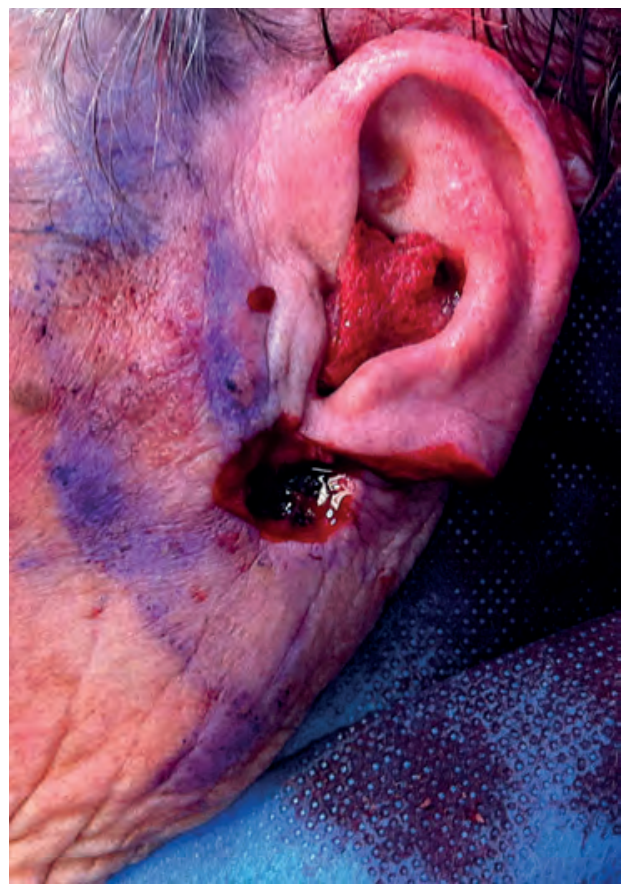

FIGURE 2 :

Surgical defect compromising the entire earlobe
The flap was raised and transposed to the recipient site (Figure 3); the lower part of this flap was fashioned to provide a new lobule with skin cover on both surfaces. Posterior covering of the earlobe was supplied by the lower folded prolongation of the flap. The secondary defect of the flap donor site was primarily sutured after generous undermining. A simple running suture using 6-0 ethilon was used to suture the flap into the primary defect (Figure 4). No postop-

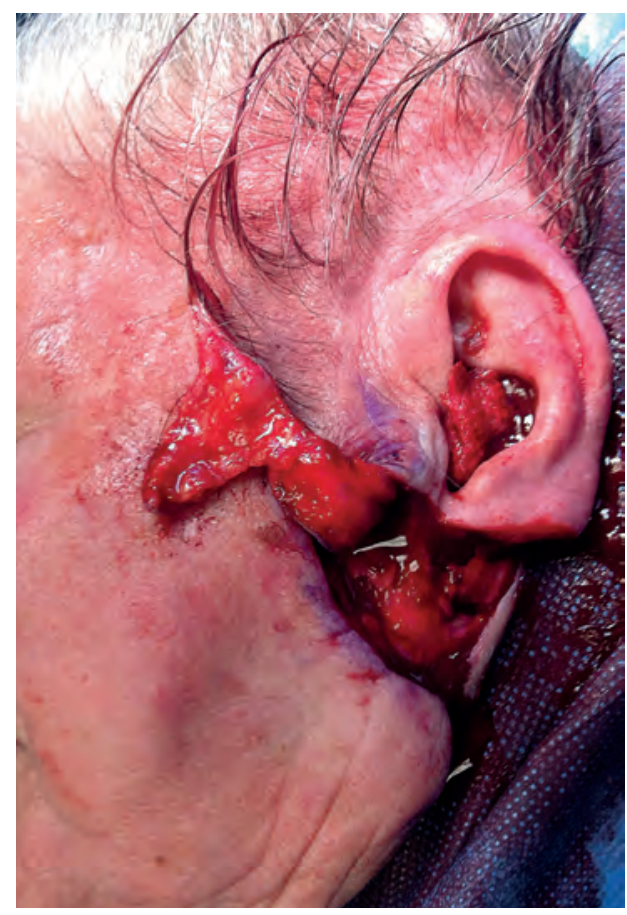

Figure 3 :

Preauricular transposition flap raised

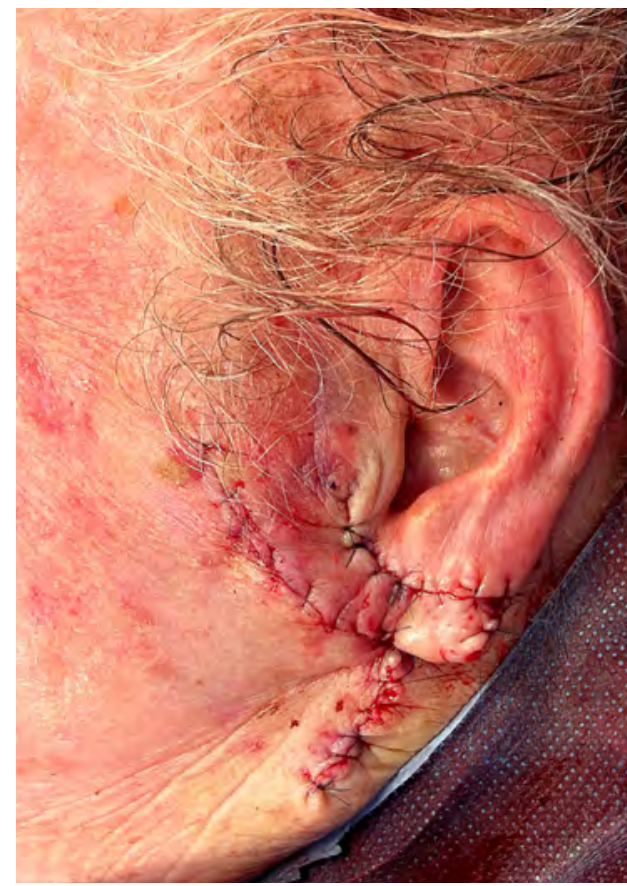

FIGURE 4 :

Flap sutured in place 
erative complications were noted. The margins of the specimen were disease-free. Figure 5 shows the clinical appearance of the surgical site 1 year after surgery.

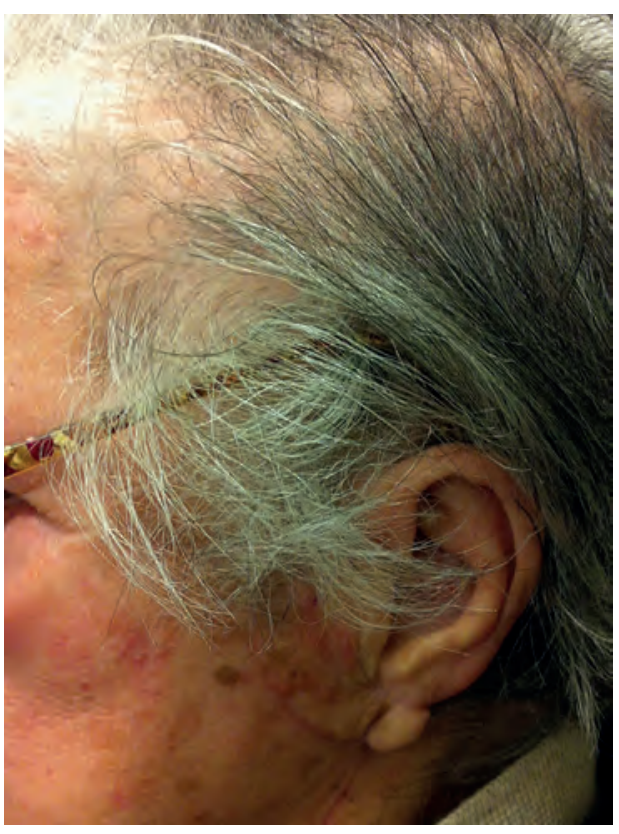

Figure 5 :

Clinical appearance of the surgical site 2 months after surgery

\section{REFERENCES}

1. Alconchel MD, Rodrigo J, Cimorra GA. A combined flap technique for earlobe reconstruction in one stage. Br J Plast Surg. 1996;49:242-4.

2. Emiroglu M, Al-Saedi M. Gavello's procedure: an old earlobe reconstruction method, revisited and touched up. Aesthetic Plast Surg. 2001;25:187-8

3. Khemani S, Rannard F, Kenyon G. Bilobar postauricular skin flap for reconstruction of the earlobe. J Laryngol Otol. 2007;121:1094-5.

4. Singh A, Singh G. Earlobe reconstruction using a Limberg flap in six ears. $\mathrm{Br} \mathrm{J}$ Plast Surg. 2003;56:33-6.

5. Mohan M, Appukuttan PK, Srinivasan A. Earlobe reconstruction with a preauricular flap. Plast Reconstr Surg. 1978;62:267-70.

6. Shen W, Cui J, Chen J, Chen H, Zou J, Ji Y. Inversion of the flap at the lower ear and restoration of the flap at postauricular skin for reconstruction of the earlobe. $J$ Craniofac Surg. 2012;23:560-2.

7. Alanis SZ. A new method for earlobe reconstruction. Plast Reconstr Surg. 1970;45:254-7.

8. Sleilati F. Immediate earlobe reconstruction with double-crossed skin flaps. J Plast Reconstr Aesthet Surg. 2006;59:1003-5.

\section{DISCUSSION}

Earlobe deformity may be congenital or, more often, acquired due to trauma, burns or surgery. Ear lobules are an important reference point for facial symmetry and they also serve decorative purposes like wearing earrings. Losing them represents an obvious aesthetic abnormality.

Earlobe reconstruction following tumor excision is a challenge for most dermatological surgeons. Several methods developed to reconstruct this deformity have borne various advantages and disadvantages. ${ }^{1-8}$ The superiorly based preauricular transposition flap is technically simple and safe. It requires only one operation (single-staged surgery) and the donor site is closed directly.

\author{
MAILING ADDRESS: \\ João Goulão \\ Av. Torrado da Silva, 2801-951 \\ Almada, Portugal \\ E-mail: goulao.joao@gmail.com
}

How to cite this article: Goulão J, Alves J. Total earlobe reconstruction with a superior based preauricular flap. An Bras Dermatol. 2016;91(3):372-4. 